\title{
Incidental testicular masses and the role of organ-sparing approach
}

\author{
Yash Narayan ${ }^{1}$, Dominic Brown ${ }^{1}$, Stella Ivaz ${ }^{1}$, Krishanu Das ${ }^{2,3}$, Mohamad Moussa ${ }^{4}$, \\ Georgios Tsampoukas ${ }^{1,2}$, Athanasios Papatsoris ${ }^{2,3}$, Noor Buchol $z^{2}$ \\ ${ }^{1}$ Department of Urology, Princess Alexandra Hospital, Harlow, UK; \\ ${ }^{2}$ U-merge Ltd. * (Urology for emerging countries), London, UK; \\ ${ }^{3}$ Consultant Urologist, Bahrain Specialist Hospital, Bahrain; \\ ${ }^{4} \mathrm{Al}$ Zahraa Hospital, University Medical Center, Lebanese University, Beirut, Lebanon. \\ * U-merge Ltd. (Urology for Emerging Countries) is an academic urological platform dedicated to facilitate knowledge transfer in urology \\ on all levels from developed to emerging countries. U-merge Ltd. is registered with the Companies House in London/ UK. www.U-merge.com
}

\begin{abstract}
Summary Objectives: The widespread use of ultrasonography for the investigation of common urological conditions, such as infertility or pain, has resulted in an increased incidence of incidental non-palpable testicular masses. The majority of these are expected to be benign therefore a conservative approach, either active monitoring or organsparing approach, is recommended. However, there are no clinical or radiological parameters which define the exact nature of such lesions and optimal patient selection criteria are lacking. In this comprehensive review we discuss the significance of incidental, small testicular masses (STMs) and the role of organ-sparing approach in the management of these lesions.

Materials and methods: A non-systematic search was performed using PubMed to identify articles that covered the following topics; clinical implications at diagnosis, role of imaging in identifying the malignant capabilities of a lesion, role of surgery and the final pathology.

Results: Incidental STMs are routinely identified following ultrasound examination of infertile men. STMs usually measure a few millimeters in size and the majority of these are benign. Therefore, strict follow up or an organ-sparing approach, with utilisation of frozen section analysis (FSA), is favored for STMs. FSA has a high correlation with final pathology and prevents unnecessary orchidectomies. Advances in imaging, namely ultrasound and magnetic resonance imaging may provide enhanced assessment of STMs and guidance intraoperatively.

Conclusions: The optimal approach is not well defined and there is no specific clinical parameter that can predict the nature of STMs. The increasing incidence of small, benign testicular masses has resulted in the development of organ-sparing surgery to investigate and manage these lesions. Organ-sparing surgery has been shown to be practical and carries excellent oncological outcomes.
\end{abstract}

KEY WORDS: Incidental testicular masses; Non-palpable; Testissparing surgery; Surveillance; ultrasound.

Submitted 25 February 2021; Accepted 5 July 2021

\section{INTRODUCTION}

Testicular germ-cell tumors (GCT) are the most common solid neoplasms in young men with an incidence of 10 per 100000 men (1). The traditional treatment for suspected tumors is radical orchidectomy and organ-sparing surgery is considered primarily in cases of bilateral tumors or monorchid patients (2).

In recent years the widespread use of ultrasound for noncancerous indications has resulted in an increase in incidental, small testicular masses (STMs) of questionable significance $(3,4)$. STMs are most efficiently characterized as non-palpable testicular lesions measuring $<25 \mathrm{~mm}$ in diameter. However, a specific size cutoff is difficult to define and the exact dimensions are still debated in the literature $(5,6)$. In this size though, the probability of benign pathology is regarded as significantly high, and thus, a stepwise approach of inguinal surgical exploration, delivery of the organ and frozen section examination is recommended. Organ-preserving surgery is preferred if the diagnosis is benign while radical orchidectomy is usually preserved if there is evidence of malignancy $(5,7,8)$.

The most common scenario on routine ultrasound is the finding of a non-palpable lesion during workup for infertility or scrotal pain, where the majority of these patients have benign lesions and a conservative approach is strongly indicated (9). Nevertheless, the management of incidental STMs warrants a critical review of the literature as there are no patient selection criteria for an organ-sparing approach, and a strict diagnostic algorithm is lacking. In this review we discuss the significance of STMs and the role of organ-sparing approach in the management of the condition.

\section{MATERIAL AND METHOdS}

We performed a non-systematic search in PubMed with the terms 'small testicular masses', 'incidental testicular masses', 'testicular sparing approach' and 'partial orchidecto$m y$ '. Only studies in English were included.

Case reports were excluded and literature reviews were used to identify additional articles. After screening the abstracts, full-text articles were evaluated in an attempt to identify studies engaging with relevant clinical topics. 


\section{ResUlts}

\section{Clinical implications at time of discovery of incidental mass}

STMs can be found at any age, ranging from childhood to adolescence and up to middle aged men (10-12). Male infertility presenting as dyspermia or the more severe azoospermia, are amongst the most frequently reported indications for ultrasound examination which results in the diagnosis of an incidental STM (13-19). Unspecified testicular or epididymal pain, an acute inflammation in the genital area, scrotal swelling, a history of trauma, varicocele, abdominal pain, hydrocele, suspicion of nephrolithiasis, gynecomastia, and follow up of cryptorchidism are also reported as indications $(8,11,12,20$ 25). Of note small masses might be discovered during the follow up of patients with previous treatment of GCT or other testicular tumors (26-28), and a prior history of cryptorchidism might unmask an undetected testicular mass during follow up $(12,15,23,29)$. In the same vein, extra attention should be given to patients with suspected retroperitoneal, extragonadal GCT as STMs might indicate a burned out primary testicular tumor (30).

\section{Role of imaging in the assessment of the malignant potential of the lesion}

The size of STMs on ultrasound usually ranges from 3 $\mathrm{mm}$ up to $25 \mathrm{~mm}(4,31)$, and the majority of these lesions will be found to be benign however malignancy cannot be excluded even in the smallest lesions $(7,17)$. In spite of this, size and risk of malignancy are strongly correlated $(5,32)$; large lesions seem to carry a greater risk of malignancy and the smaller the nodule, the less likely it is to be malignant $(5,8,33)$. Using a cutoff of 5 $\mathrm{mm}$ in infertile patients with STMs, Bieniek et al. reported that the majority of these masses did not show significant growth during follow up and could be safely surveilled (19). In such cases Toren et al. observed that initial larger size and vascular flow, as identified on ultrasound, were factors associated with intervention during follow up (14). Similarly Scandura et al. reported that lesions smaller than $5 \mathrm{~mm}$ are always benign whereas malignancy can be found in one third of cases in lesions measuring 5-10 $\mathrm{mm}$ (29). In another study, Gentile and colleagues stated that the malignant probability of STMs, measuring less than $10 \mathrm{~mm}$, is smaller than $10 \%$ whilst the risk increases sevenfold with each millimeter (5). However other authors have advised that inguinal exploration and frozen section analysis (FSA) are essential even in small masses, less than $5 \mathrm{~mm}$, as malignancy cannot be excluded definitely (11). This is because the most common ultrasonographic appearance is of an hypoechoic lesion, a finding which should be regarded as non-specific $(33,34)$.

However Dell'Atti et al. reported that malignant and benign lesions differ significantly as cancerous lesions were strongly hypoechoic, in appearance, in comparison to benign lesions (89.8\% vs $39.3 \%$, p > 0.001) and calcified lesions were strongly associated with benign tumors (25). Others have suggested that extra attention should be given to echogenic foci as these might represent burned out tumors and in such cases, the retroperitoneal space should be evaluated $(30,35)$. The presence of vascularization on Color Doppler Ultrasound is also strongly associated with malignancy whereas small, inflammatory lesions usually do not exhibit any flow (28). Contrastenhanced testicular ultrasound, if available, is a costeffective imaging method for the characterization of nonpalpable testicular lesions (36). With the enhancement of diagnostic performance, some authors have reported that the combination of different ultrasonographic techniques in a multiparametric fashion offers excellent sensitivity and specificity in the assessment of STMs. The combination of elastography with contrast-enhanced scrotal ultrasound demonstrated a sensitivity of $100 \%$, a specificity of $93 \%$, and a positive likelihood ratio of 14.3 for malignancy (37). Magnetic Resonance Imaging (MRI) might also increase the diagnostic accuracy in its ability to distinguish between fat, fluid, fibrosis, cystic and solid lesions; gadolinium contrast enhancement technique may also be able to differentiate between benign and malignant lesions $(6,20)$. Thus, MRI can assist the decision making in cases of diagnostic uncertainty favoring a testicular sparing approach in patients with low suspicion of malignancy $(6,38,39)$.

\section{The operative technique}

If an intervention is scheduled, the procedure follows the same principles as for radical orchidectomy. The testis is exposed, mobilized and exteriorized through an inguinal incision. The clamping of the spermatic cord is controversial as seeding of malignant cells is mostly related to the nature of the tumor and not with the manipulation alone (40). If cross-clamping is performed before delivery, the testis should be protected from warm ischemia, with an iced pack, as warm ischemia may cause irreversible damage of the testicular parenchyma thus impairing both the endocrine and exocrine functions of the organ (15). There are two possible approaches; one in an avascular plane on the anterior aspect of the organ exposing the whole parenchyma or alternatively a smaller incision directly onto the tumor (40). Intraoperatively the use of a linear ultrasound transducer (7.5-15 MHz) can guide the excision and also ensure adequate preservation of testicular parenchyma. Some authors perform real-time ultrasonography to facilitate the placement of a stereotaxic hook-shaped needle which can guide the resection $(15,20)$. Either way the tumor is excised and sent for FSA leaving 2-3 mm safe surgical margins (15, 41). Frozen-section biopsies should be taken from the borders of the lesion to ensure adequate resection and as a rule, if there is not enough parenchyma for frozen-section biopsies then preservation of the organ is not recommended (40). If the benign nature of a lesion is confirmed or the removal of a malignant tumor is completed, the testicle is placed back into the scrotum otherwise a radical orchidectomy is performed for all other indications (42).

\section{Significance of frozen section analysis, testis-sparing surgery and random biopsies}

FSA is regarded as indispensable during organ-sparing surgery in patients with indeterminate STMs or if the diagnosis of malignancy is in doubt, regardless of size (8, 43). The correlation of FSA with the final pathology is high, the procedure is dependable, and FSA is not limit- 
ed by size $(5,31,44,45)$. It could be stated that FSA prevents unnecessary orchidectomies and enables preservation of the testicular parenchyma $(5,46)$. Therefore, the optimal treatment of STMs should include FSA to guide management of the extricated tumour, in the form of testis-sparing surgery (TSS) or radical orchidectomy. If a GCT is identified on FSA, TSS should be considered if imperative indications are met (synchronous bilateral tumours, metachronous tumours in solitary testicle) in order to attempt preservation of fertility and hormonal function $(5,8)$. In that scenario, field biopsies in a systematic and random manner are also mandatory as in situ germ cell neoplasia may be present elsewhere, even a long distance from the initial tumor. This finding reflects the malignant spread of the tumor and warrants treatment with adjuvant radiotherapy $(12,33)$.

\section{The final pathology}

In the final specimen, benign lesions are found in most patients and in some studies the incidence is as high as $80 \%(5,21,34,47)$. Leydig cell tumor is the most frequently reported pathology in non-malignant cases (5, $11,15,21,27,48)$. Other diagnoses include fibrosis, epidermoid cysts, granulomatous orchitis (25), ectopic nodule of adrenal cortex, adenomatous tumour and fibrous pseudotumor (29). Sertoli tumor and hemorrhagic infiltration with no evidence of tumor have also been reported (49). Of the malignant lesions, pure seminoma along with the presence of distant carcinoma in situ is the most commonly reported finding $(11,23,28,49)$. Leiomyoma, mixed germ cell tumours including embryonal carcinoma, mature teratoma, and liposarcoma have also been reported in the final specimen $(27,50,51)$.

\section{Discussion}

Although there is no specific clinical parameter that can predict the exact nature of STMs, those that are non-palpable are usually benign (24). Palpability, raised testicular markers, hypoechoicity on ultrasound images, and larger size are considered risk factors for malignancy (52). Specific patient groups such as infertile patients seem to enjoy a favorable prognosis thus justifying the avoidance of unnecessary surgery. Eifler et al. and Lagabrielle et al. found that patients with small, incidental masses identified during work-up for infertility, can usually be monitored with repeat ultrasound and additionally surgical intervention can be performed safely should the clinical need arise $(13,16)$. In such cases, where intervention is required, the simultaneous performance of TSS and microscopic testicular tissue extraction has been proposed by some authors, without causing any significant complication or compromising the remaining testicular volume (15). With regards to the development of secondary hypogonadism, no significant change in plasma testosterone has been reported and secondary hypogonadism should not be expected in patients with bilateral testis undergoing TSS for STMs $(11,51)$. However it seems that patients undergoing TSS for malignant lesions are at higher risk of secondary hypogonadism as this may be found in up to $15 \%$ of cases (42). Similarly the effect on endocrine function is comparative even when a radi- cal approach is performed and it increases significantly as the treatment is escalated (53). In this regard, it seems that the approach alone is not entirely responsible, rather it is the relative risk of malignancy that affects the outcome. Importantly the oncological prognosis in patients with malignancy is regarded to be excellent (54).

Therefore, it seems apparent that an organ sparing approach or a surveillance protocol is optimal for patients with incidental testicular masses. Some authors have attempted to provide specific recommendations regarding the management of STMs such as the diagnostic algorithm proposed by Scandura et al. in patients with STMs less that $10 \mathrm{~mm}$. They state that if tumor markers are negative an ultrasound should be repeated in 3 months, and if there is no change then the patient can be discharged from further follow up with the recommendation of selfexamination. If there is an increase in size, of less than $20 \%$ of the original, an ultrasound is repeated in 3 months and if no change is identified the patient is discharged as previously. Alternatively if there is a greater than 20\% increase in size then FSA is advised (29).

\section{Conclusions}

The increasing incidence of small, non-palpable and benign testicular masses has resulted in the development of organ sparing surgery to investigate and treat these lesions. The optimal approach is not well defined however patients who present for routine investigation of infertility or scrotal pain who have no palpable nodules, negative testicular markers, and lesions only a few millimeters in size are likely to have benign pathology. In such cases options include either an active monitoring program or an organ sparing approach. The latter has been shown to be practicable and reproducible and carries excellent oncological and functional outcomes.

\section{REFERENCES}

1. Heidenreich A, Paffenholz P, Nestler T, Pfister D. European Association of Urology guidelines on testis cancer: important take home messages. Eur Urol Focus. 2019; 5:742-4.

2. La Rocca R, Capece M, Spirito L, et al. Testis-sparing surgery for testicular masses: current perspectives. Minerva Urol Nefrol. 2019; 71:359-64.

3. Corrie D, Mueller EJ, Thompson IM. Management of ultrasonically detected nonpalpable testis masses. Urology. 1991; 38:429-31.

4. Buckspan MB, Klotz PG, Goldfinger M, et al. Intraoperative ultrasound in the conservative resection of testicular neoplasms. J Urol. 1989; 141:326-7.

5. Gentile $G$, Rizzo M, Bianchi L, et al. Testis sparing surgery of small testicular masses: retrospective analysis of a multicenter cohort. J Urol. 2020; 203:760-766.

6. Brown D, Tsampoukas G, Popov EP, et al. The role of radiological surveillance in the conservative management of incidental small testicular masses: A systematic review. Arab J Urol. 19:179-185,

7. Horstman WG, Haluszka MM, Burkhard TK. Management of testicular masses incidentally discovered by ultrasound. J Urol. 1994; 151:1263-5.

8. Khan MJ, Bedi N, Rahimi MNC, Kalsi J. Testis sparing surgery for 
small testicular masses and frozen section assessment. Cent Eur J Urol. 2018; 71:304-9.

9. Paffenholz P, Held L, Loosen SH, et al. Testis sparing surgery for benign testicular masses: diagnostics and therapeutic approaches. J Urol. 2018; 200:353-60.

10. Caldwell BT, Saltzman AF, Maccini MA, Cost NG. Appropriateness for testis-sparing surgery based on the testicular tumor size in a pediatric and adolescent population. J Pediatr Urol. 2019; 15:70.e1-70.e6.

11. Müller T, Gozzi C, Akkad T, et al. Management of incidental impalpable intratesticular masses of $\leq 5 \mathrm{~mm}$ in diameter. BJU Int. 2006; 98:1001-4.

12. Pierconti F, Martini M, Grande G, et al. Germ cell neoplasia in situ (GCNIS) in testis-sparing surgery (TSS) for small testicular masses (STMs). Front Endocrinol (Lausanne). 2019; 10:512.

13. Eifler JBJ, King P, Schlegel PN. Incidental testicular lesions found during infertility evaluation are usually benign and may be managed conservatively. J Urol. 2008; 180:261-4

14. Toren PJ, Roberts M, Lecker I, et al. Small incidentally discovered testicular masses in infertile men--is active surveillance the new standard of care? J Urol. 2010; 183:1373-7.

15. Hallak J, Cocuzza M, Sarkis AS, et al. Organ-sparing microsurgical resection of incidental testicular tumors plus microdissection for sperm extraction and cryopreservation in azoospermic patients: surgical aspects and technical refinements. Urology. 2009; 73:887-91.

16. Lagabrielle S, Durand X, Droupy S, et al. Testicular tumours discovered during infertility workup are predominantly benign and could initially be managed by sparing surgery. J Surg Oncol. 2018; 118:630-5.

17. Colpi GM, Carmignani L, Nerva F, et al. Testicular-sparing microsurgery for suspected testicular masses. BJU Int. 2005; 96:67-9.

18. Carmignani L, Gadda F, Mancini M, et al. Detection of testicular ultrasonographic lesions in severe male infertility. J Urol. 2004; 172:1045-7.

19. Bieniek JM, Juvet T, Margolis M, et al. Prevalence and management of incidental small testicular masses discovered on ultrasonographic evaluation of male infertility. J Urol 2018; 199:481-6.

20. Avci A, Erol B, Eken C, Ozgok Y. Nine cases of nonpalpable testicular mass: An incidental finding in a large scale ultrasonography survey. Int J Urol. 2008; 15:833-6.

21. Shilo Y, Zisman A, Lindner A, et al. The predominance of benign histology in small testicular masses. Urol Oncol. 2012; 30:719-22.

22. Brunocilla E, Gentile G, Schiavina R, et al. Testis-sparing surgery for the conservative management of small testicular masses: an update. Anticancer Res. 2013; 33:5205-10.

23. Fabiani A, Filosa A, Fioretti F, et al. Diagnostic ultrasound-guided excisional testicular biopsy for small $(<1 \mathrm{~cm})$ incidental nodules. A single institution experience. Arch Ital di Urol Androl. 2014; 86:373-7.

24. Carmignani L, Gadda F, Gazzano G, et al. High incidence of benign testicular neoplasms diagnosed by ultrasound. J Urol. 2003; 170:1783-6.

25. Dell'Atti L, Fulvi P, Benedetto Galosi A, Galosi AB. Are ultrasonographic measurements a reliable parameter to choose non-palpable testicular masses amenable to treatment with sparing surgery? J BUON. 2018; 23:439-43.

26. Assaf GJ. Non-palpable testicular lesion: the case for testicular preservation. Can J Urol. 2006; 13:3034-8.
27. De Stefani S, Isgro G, Varca V, et al. Microsurgical testis-sparing surgery in small testicular masses: seven years retrospective management and results. Urology. 2012; 79:858-62.

28. Drudi FM, Maghella F, Martino G, et al. Detection of small testicular masses in monorchid patients using US, CPDUS, CEUS and US-guided biopsy. J Ultrasound. 2016; 19:25-8.

29. Scandura G, Verrill C, Protheroe A, et al. Incidentally detected testicular lesions $<10 \mathrm{~mm}$ in diameter: can orchidectomy be avoided? BJU Int. 2018; 121:575-82.

30. Comiter C V, Renshaw AA, Benson CB, Loughlin KR. Burned-out primary testicular cancer: sonographic and pathological characteristics. J Urol. 1996; 156:85-8.

31. Shilo Y, Zisman A, Raz O, et al. Testicular sparing surgery for small masses. Urol Oncol. 2012; 30:188-91.

32. Connolly SS, D'Arcy FT, Bredin HC, et al. Value of frozen section analysis with suspected testicular malignancy. Urology. 2006; 67:162-5.

33. Hopps C V, Goldstein M. Ultrasound guided needle localization and microsurgical exploration for incidental nonpalpable testicular tumors. J Urol. 2002; 168:1084-7.

34. Rolle L, Tamagnone A, Destefanis P, et al. Microsurgical "testissparing" surgery for nonpalpable hypoechoic testicular lesions. Urology. 2006; 68:381-5.

35. Sheynkin YR, Sukkarieh T, Lipke M, et al. Management of nonpalpable testicular tumors. Urology. 2004; 63:1163-7.

36. Rübenthaler J, Kim SH, Kunz WG, et al. Should we use contrastenhanced ultrasound (CEUS) for the characterization of nonpalpable testicular lesions? An analysis from a cost-effectiveness perspective. Ultraschall Med. 2020; 41:668-674.

37. Auer T, De Zordo T, Dejaco C, et al. Value of multiparametric US in the assessment of intratesticular lesions. Radiology. 2017; 285:640-9.

38. Obembe OO, Patel MD. Value of dynamic, contrast-enhanced MRI and intraoperative ultrasound for management of a nonpalpable, incidental, testicular Leydig-cell tumor. Radiol Case Reports. 2010; 5:432.

39. Thomas LJ, Brooks MA, Stephenson AJ. The role of imaging in the diagnosis, staging, response to treatment, and surveillance of patients with germ cell tumors of the testis. Urol Clin North Am. 2019; 46:315-31.

40. Heidenreich A, Angerer-Shpilenya M. Organ-preserving surgery for testicular tumours. BJU Int. 2012; 109:474-90.

41. Powell TM, Tarter TH. Management of nonpalpable incidental testicular masses. J Urol. 2006; 176:96-8.

42. Heidenreich A, Weissbach L, Holtl W, et al. Organ sparing surgery for malignant germ cell tumor of the testis. J Urol. 2001; 166:2161-5.

43. Tuygun C, Ozturk U, Goktug HNG, et al. Evaluation of frozen section results in patients who have suspected testicular masses: a preliminary report. Urol J. 2014; 11:1253-7.

44. Benelli A, Varca V, Derchi L, et al. Evaluation of the decisionmaking process in the conservative approach to small testicular masses. Urologia. 2017; 84:83-7.

45. Matei DV, Vartolomei MD, Renne G, et al. Reliability of frozen section examination in a large cohort of testicular masses: what did we learn? Clin Genitourin Cancer. 2017; 15:e689-96.

46. Subik MK, Gordetsky J, Yao JL, et al. Frozen section assessment 
in testicular and paratesticular lesions suspicious for malignancy: its role in preventing unnecessary orchiectomy. Hum Pathol. 2012; 43:1514-9.

47. Giannarini G, Dieckmann K-PP, Albers P, et al. Organ-sparing surgery for adult testicular tumours: a systematic review of the literature. Eur Urol. 2010; 57:780-90.

48. Steiner H, Holtl L, Maneschg C, et al. Frozen section analysisguided organ-sparing approach in testicular tumors: technique, feasibility, and long-term results. Urology. 2003; 62:508-13.

49. Galosi AB, Fulvi P, Fabiani A, et al. Testicular sparing surgery in small testis masses: A multinstitutional experience. Arch Ital di Urol Androl. 2016; 88:320-4.

50. Ayati M, Ariafar A, Jamshidian H, et al. Management of non- palpable incidental testicular masses: Experience with 10 cases. Urol J. 2013; 11:1892-5.

51. Gentile G, Brunocilla E, Franceschelli A, et al. Can testis-sparing surgery for small testicular masses be considered a valid alternative to radical orchiectomy? A prospective single-center study. Clin Genitourin Cancer. 2013; 11:522-6.

52. Esen B, Yaman MO, Baltaci S. Should we rely on Doppler ultrasound for evaluation of testicular solid lesions? World J Urol. 2018; 36:1263-6

53. Jacobs LA, Vaughn DJ. Hypogonadism and infertility in testicular cancer survivors. J Natl Compr Canc Netw. 2012; 10:558-63.

54. Pfister D, Paffenholz P, Haidl F. Testis-sparing surgery in patients with germ cell cancer: indications and clinical outcome. Oncol Res Treat. 2018; 41:356-8.

\section{Correspondence}

Yash Narayan, MD

y.narayan@nhs.net

Dominic Brown, MD

dominic.brown5@nhs.net

Stella Ivaz, MD

stellaivaz@hotmail.com

Georgios Tsampoukas, MD

tsampoukasg@gmail.com

Department of Urology, Princess Alexandra Hospital, Harlow (UK)

Hamstel Road, Harlow, United Kingdom, CM20 1QX

Krishanu Das, MD

Consultant Urologist, Bahrain Specialist Hospital, Bahrain

Mohamad Moussa, MD

mohamad.moussa@zhumc.org.lb

Al Zahraa Hospital, University Medical Center, Lebanese University, Beirut (Lebanon)

Athanasios Papatsoris, MD

agpapatsoris@yahoo.gr

U-merge Ltd., London (UK)

Noor Bucholz, MD

noor.buchholz@gmail.com

U-merge Ltd., London (UK) 